\title{
La polifonía en el discurso
}

Luisa Puig*

Tradicionalmente la enseñanza del español como lengua materna se ha desarrollado, por una parte, a nivel de la oración y, por la otra, haciendo énfasis en sus aspectos morfosintácticos. En la época moderna esta perspectiva se ha diversificado y a las categorías de la lengua se han agregado los modos de organización del discurso (Charaudeau, 1992), es decir, los procedimientos de "puesta en escena" del acto de comunicación, procedimientos que corresponden básicamente con cuatro finalidades: enunciar, describir, narrar y argumentar.

El estudio del discurso ha llevado a considerar nuevas concepciones sobre la práctica de la lengua por los sujetos hablantes. Tal es el caso de la concepción pragmática que considera que el estudio del discurso, es decir, del lenguaje en contexto, se rige por ciertas ideas fundamentales que, independientemente de la teoría que se trate, comparten los especialistas la idea de que la enunciación es fundamentalmente reflexiva (lo que significa que no habla del mundo más que hablando también de sí misma); la idea de que el lenguaje es una actividad e incluso una interactividad (lo que implica que el discurso se concibe, más que como un instrumento de comunicación y de transmisión de informaciones, como una red compleja de estrategias que pone en marcha el enunciador y ante las que reacciona el coenunciador); y la idea de que la actividad verbal es una realidad institucional regida por normas tanto de carácter lingüístico como social (Maingueneau, 2001).
Estas hipótesis de partida llevaron al desarrollo de teorías que transformaron y diversificaron su objeto de estudio al abordar un sinfín de problemáticas relacionadas con la enunciación, la subjetividad en el lenguaje, los actos del lenguaje, la interacción discursiva, los implícitos discursivos, la gramática textual, los modos de organización argumentativa, etc.

Un lugar importante en este conglomerado de teorías y perspectivas lo ocupan las problemáticas que tienen que ver con la manera como el autor de un enunciado pone en escena a diferentes personajes a propósito de los cuales manifiesta diversas actitudes, fenómeno que ha dado lugar al desarrollo de las teorías de la polifonía en el discurso.

Los primeros trabajos en lingüística que manifiestan la existencia de discursos compuestos de varias voces datan de finales de los años setenta, en particular con los trabajos de Ann Banfield, Jacqueline Authier-Revuz y Marc Plénat. Estos primeros estudios se interesaron en problemas relacionados con el estilo indirecto libre y dieron paso al desarrollo de diversas teorías polifónicas (Anscombre, 2009, p. 12).

Desde luego que en este terreno es necesario referirnos también a la obra de Mijail Bajtín. En particular reconocer que este autor fue quien propuso, como punto de partida, el rechazo de la idea dominante hasta entonces de la unicidad del sujeto hablante. Sin embargo, como veremos, el sentido que atribuye a las nociones de dialogismo y de polifonía

* La autora está vinculada al Instituto de Investigaciones Filológicas, Universidad Nacional Autónoma de México (UNAM) Correo electrónico: puig@unam.mx 
se aleja de las perspectivas que se han desarrollado en lingüística. Así, a propósito de la poética de Dostoievski, Bajtín (1988) considera que "la pluralidad de voces y conciencias independientes e inconfundibles, la auténtica polifonía de voces autónomas, viene a ser, en efecto, la característica principal de las novelas de Dostoievski” (p.16).

En cuanto al dialogismo este autor lo define como la presencia simultánea de diversas autorías, lenguajes, puntos de vista, visiones del mundo y voces sociales e históricas en un mismo discurso e incluso en un mismo enunciado; noción de carácter sobre todo sociológico e ideológico, que hace referencia a un discurso ajeno que se superpone a la enunciación de otro. Esta concepción, como afirma Ducrot (2009, p. 35), rompe la unidad semántica del enunciado, que en las teorías lingüísticas se refleja en la función protagónica del locutor, en sus actitudes a propósito de los puntos de vista que despliega en el enunciado.

Como en cualquier campo de estudio, las teorías sobre la polifonía han ido evolucionando a través del tiempo. Al respecto es interesante recordar la manera como Benveniste concebía la reflexión sobre el lenguaje. En el prólogo al primer tomo de su libro Problemas de lingüística general explica que si los estudios reunidos en el volumen se presentan "como 'problemas', es porque en conjunto, y cada uno por su lado, aportan sendas contribuciones a la gran problemática del lenguaje”. Con esta advertencia, como lo explica Gérard Dessons (2006), Benveniste quería señalar que sus aportaciones, más que "construcciones de diversos saberes, eran actos de investigación en un ámbito en el que el lenguaje no es una 'positividad' por conocer de una vez por todas, sino una 'problemática"' (p. 10), es decir, a la vez un objeto de estudio arduo, complejo, y un interrogante que no es posible resolver definitivamente, sino que se renueva constantemente con cada investigación.

Con esta idea en mente los estudios sobre la polifonía han permitido sacar a la luz una serie de problemáticas que señala Jean-Claude Anscombre. Este autor divide el desarrollo teórico en este campo en tres etapas (2009): la primera corresponde con el nacimiento de la perspectiva polifónica; la segunda, alrededor de los años ochenta, que lleva a la elaboración de lo que él llama la teoría "standard"; la tercera y más reciente para este autor corresponde a una renovación de la teoría, gracias a la irrupción de los fenómenos de mediatividad. ${ }^{1}$

Las teorías sobre la polifonía han dividido su campo de estudio en tres niveles: "a) el nivel de la producción empírica del enunciado, b) el nivel de la responsabilidad del enunciado y c) el nivel de los actores que el enunciado y su responsable ponen en escena" (Anscombre, 2009, p. 16).

En cada uno de ellos se plantean diversas problemáticas que Anscombre (2009, p. 21) ha reagrupado en una serie de cuestiones fundamentales:

1. En relación con la naturaleza epistemológica de una teoría polifónica, ¿dónde debe situarse dicha teoría: en la pragmática en el sentido estricto o en la semántica, incluyendo en esta a la pragmática integrada?

2. La segunda opción lleva a otra problemática: ¿todos los enunciados son polifónicos o solo algunos de ellos?

3. ¿Cómo se pueden identificar a los diferentes locutores, enunciadores, puntos de vista? ¿Es posible proponer, al respecto, criterios lingüísticos confiables?

1 Anscombre se refiere a los trabajos de Guentcheva, Lénonciation médiatisée (1996), al número 102 de Langue française "Les sources du savoir" dirigido por Dendale y Tasmowski (1994), al trabajo de Coltier y Dendale "La modalisation du discours de soi: éléments de description sémantique des expressions pour moi, selon moi, et à mon avis", Langue Française 142, (2004), en fin, a los estudios sobre las formas sentenciosas de Anscombre "Parole proverbiale et structures métriques" Langages 139, (2000) y Kleiber “Sur le sens des proverbes", Langages 139, (2000), entre otros. 
4. ¿Cuál es la naturaleza semántica de los enunciadores y la de los puntos de vista? ¿Qué tipo de relaciones se establecen entre estos dos tipos de entidades?

5. ¿Qué relaciones existen entre el locutor y sus enunciadores? ¿Es posible establecer, a su vez, relaciones entre los enunciadores?

Todas estas problemáticas han sido objeto de un debate permanente entre las diversas perspectivas teóricas.

Presentaré aquí dos opciones teóricas: la de Oswald Ducrot, uno de los fundadores de la vía polifónica en pragmasemántica y la de la ScaPoLine (teoría escandinava de la polifonía lingüística) que, en palabras de Ducrot, es una construcción teórica que con toda coherencia y rigor respeta la unidad semántica del enunciado, la "idea de una palabra a la vez múltiple y controlada" y que, por otra parte, logra "relacionar la polifonía interna propia de los enunciados a la polifonía de los textos que conforman estos enunciados" 2 .

\section{Oswald Ducrot: la teoría polifónica de la enunciación ${ }^{3}$}

Esta teoría postula tres tesis fundamentales (Ducrot, 2001):

La primera cuestiona y tiene como objeto reemplazar un postulado implícito de la lingüística moderna: el de la unicidad del sujeto del enunciado. Al respecto, Ducrot propone una primera distinción entre el sujeto empírico y el locutor.

Como su nombre lo indica, el sujeto empírico es el autor efectivo, el ser de la realidad social que produce el enunciado, personaje que, de hecho, es difícil, e incluso a veces imposible, determinar. En efecto, es muy común que la conversación cotidia- na consista en retomar lo que otro dijo, o lo que se oye en los medios de comunicación o se lee en los periódicos, por consiguiente no siempre somos, en realidad, los verdaderos sujetos empíricos de los enunciados que emitimos.

El locutor, en cambio, es un concepto de orden puramente lingüístico. Se trata del presunto responsable del enunciado. En otras palabras, es el ser a quien se le atribuye, en el sentido mismo del enunciado, la responsabilidad de la enunciación (lo que significa, en términos ducronianos, que el sentido del enunciado comporta una descripción de su enunciación). Lo designan las marcas de la primera persona y puede tratarse de un personaje ficticio que el sentido del enunciado exhibe como su autor.

La pertinencia de la distinción locutor/sujeto empírico estriba en que estas dos nociones no siempre son equivalentes. Así, por ejemplo, cuando una madre manda a su hijo con otra persona para que le diga a esa persona que le dé un tenmeacá, el sujeto empírico del delocutivo léxico (la madre) transmite un mensaje a la otra persona, presentando a su hijo como locutor del enunciado; en otros términos, la madre hace hablar a su hijo en este enunciado.

Esta distinción corresponde a la que utiliza Genette en el análisis literario entre el autor y el narrador. Mientras que el autor

[...] imagina o inventa sus acontecimientos, el narrador los refiere, entendiendo por esto [...], ya sea que reproduce recuerdos (pretendidos) - en el caso de un relato en pasado-, o que da una forma lingüística a lo que supuestamente vive o constata -en ciertos relatos en presente-. (Ducrot, 1984, p. 207)

La segunda tesis en que se funda la teoría polifónica de la enunciación consiste en afirmar, como es de esperarse, que ciertos enunciados presentan una pluralidad de puntos de vista, mientras que otros

2 Ducrot, prefacio a Henning Nølke, Kjersit Fløttum, Coco Norén, ScaPoLine. La théorie scsndinave de la polyphonie linguistique, 2004, p. 10 3 Ducrot ha tratado este tema en diversas publicaciones: cf., por ejemplo, Ducrot et al. 1980, Ducrot 1984, Ducrot 1988, Ducrot 1996. 
pueden no hacerlo. La tercera tesis postula que el sentido del enunciado muestra al locutor teniendo diversas actitudes en relación con esos puntos de vista: ya sea de adhesión, de rechazo o de distanciamiento en diferentes grados.

Una originalidad de la posición que sostiene este autor es la de introducir "intermediarios" entre el locutor y los puntos de vista que presenta el sentido del enunciado; Ducrot los llama enunciadores ${ }^{4}$. En este caso no se trata de personajes propiamente dichos, sino de "voces" que exhiben el enunciado. A cada punto de vista corresponde un enunciador, el cual se identifica como el origen de dicho punto de vista: "por definición, el enunciador se adhiere [...] al punto de vista que se le atribuye y no puede distanciarse de él" (Ducrot 2001, p. 20).

Mientras que, para la teoría de los actos de habla el sentido de un enunciado lo conforman una fuerza ilocucionaria y un contenido proposicional y, por ende, cada enunciado muestra generalmente una sola actitud del locutor indicada por el valor ilocucionario de dicho enunciado ${ }^{5}$, en la teoría de la polifonía un enunciado puede presentar una multitud de puntos de vista diferentes, y el locutor es capaz de tomar diversas actitudes en relación con todos esos puntos de vista (Ducrot 1988, p. 68).

El sentido del enunciado presenta al locutor como responsable del enunciado y, por lo tanto, como el que da existencia a los enunciadores y organiza los puntos de vista. Las actitudes que el locutor mantiene con los puntos de vista están mediatizadas por las actitudes que guarda con los enunciadores. Así, el locutor puede hacer aparecer a un enunciador como su portavoz (cuando la adhesión del primero al punto de vista del segundo es completa); en ese caso, la enunciación se presenta como imponiendo el punto de vista de ese enunciador. Pero también es posible que el locutor solo otorgue su acuerdo al punto de vista de un determinado enunciador o, incluso, que se oponga a este, o simplemente que lo considere como un objeto de deseo, de temor, de ira, de admiración, etcétera ${ }^{6}$.

Pero la responsabilidad del locutor que muestra el sentido del enunciado no solamente concierne estas diversas actitudes; la elección de los enunciadores $-\mathrm{y}$, por consiguiente, de los respectivos puntos de vista - también aparece como suya. Igual responsabilidad asume el locutor en lo que respecta a las indicaciones sobre la identidad de los enunciadores: ya vimos que, en algunos casos, se identifica con tal o cual enunciador $y$, a su vez, identifica al alocutario o a un tercero con otro diferente.

Ducrot hace uso de la noción de polifonía para describir los más variados hechos lingüísticos, $\mathrm{y}$ para mostrar la pertinencia de las distinciones que introduce.

La negación es uno de los fenómenos que ilustran más contundentemente la pertinencia de una concepción polifónica de la lengua. Un enunciado no $p$ presenta una especie de diálogo cristalizado en el que aparecen dos puntos de vista que sostienen dos enunciadores: E1 afirma $p$ y E2 se opone a E1.

Existen una serie de hechos lingüísticos que avalan esta descripción (Ducrot, 1988, pp. 23-29; Ducrot, 1996, pp. 75-99). Veamos, por ejemplo, el empleo de la expresión adversativa por el contrario, en un enunciado como:

Juan no tocó en el concierto, por el contrario, declinó la invitación.

4 Término elegido arbitrariamente y que, por consiguiente, no alude a un supuesto productor del enunciado.

5 Sin olvidar, desde luego, que un enunciado puede mostrar más de un valor ilocucionario.

6 Es importante subrayar que, dado que el locutor es un ser de naturaleza puramente discursiva, el sentido del enunciado es el que lo presenta como asumiendo las diversas actitudes en relación con los enunciadores (que son otros tantos seres meramente discursivos; Ducrot también los define como "puntos de perspectiva abstractos"). 
Lo sorprendente es que los dos segmentos que relacionan la expresión adversativa en realidad no se oponen entre sí, incluso del hecho de declinar la invitación se deduce que Juan no tocó en el concierto. Para entender en donde se sitúa dicha oposición es necesario partir de una descripción polifónica del primer segmento, ya que por el contrario contrapone el punto de vista positivo subyacente en la negación con el punto de vista que introduce la expresión adversativa en el segundo segmento.

Otro caso es el de ciertos pronombres en su uso anafórico. Si ampliamos el enunciado anterior:

Juan no tocó en el concierto, por el contrario, declinó la invitación, y lo siento porque eso me habría gustado enormemente.

Podemos darnos cuenta que mientras que el primero (lo) remite al hecho de que Juan no tocó, es decir, al punto de vista negativo de E2, el segundo (eso) hace referencia al punto de vista positivo que sostiene E1.

Por consiguiente, al analizar la naturaleza de los posibles encadenamientos, tanto el empleo de por el contrario como el del demostrativo, da cuenta de la presencia de un enunciador positivo subyacente en la negación.

Ducrot (1984, p. 210; 1988, p. 20) se interesó en llevar a cabo una descripción polifónica del humor y de la ironía. Ahora bien, aun cuando en estos casos no se trate de fenómenos de lengua sino de empleos particulares de la lengua, el carácter universal de las expresiones humorísticas e irónicas impone la necesidad de incluirlas en una descripción de la significación lingüística.

Sin pretender proponer un modelo que dé cuenta de todos los empleos de lo que podría llamarse el humor, Ducrot considera que un enunciado humorístico debe cumplir con tres condiciones directamente ligadas a una interpretación polifónica:

1. Entre los puntos de vista que expresa el enunciado por lo menos uno es absurdo, insostenible.
2. El locutor no se identifica con el punto de vista absurdo.

3. El enunciado no muestra ningún otro punto de vista que se oponga a la referencia del absurdo, es decir, no presenta ningún enunciador que se oponga o rectifique el punto de vista absurdo.

Como sabemos, las fronteras entre el humor y la ironía son débiles; por lo tanto serán irónicos los enunciados humorísticos en los que el punto de vista absurdo se atribuye a un determinado personaje con el fin de ridiculizarlo. Ilustremos esta descripción con la siguiente conseja:

Un pretendiente lleva serenata a su enamorada, a la que hizo enojar, para tratar de reconciliarse con ella. El nerviosismo lo lleva a ingerir no poco del espirituoso neutle que llevan los músicos que contrató. Ya beodo y emocionado, y mientras los mariachis tocan y cantan, empieza a gritar repetidas veces, bajo el balcón de la muchacha y a altas horas de la noche: “¡Te quiero, ramera!, ¡Te adoro, cabrona!” De repente, en medio de los improperios, se asoma por la ventana el padre de la chica - con el respetable camisón largo y el gorro de dormir- y le dice: "Joven, le agradezco mucho su serenata, pero me permito recordarle que la señorita, mi hija, responde al nombre de Ramona Cabrera".

En este cuento hay dos momentos que producen hilaridad: por una parte, cuando el joven se dirige a su enamorada y, al mismo tiempo que le lleva serenata, se pone a insultarla; por la otra, cuando el padre de la muchacha hace cortésmente la aclaración sobre su nombre.

En un primer momento, al lanzar los improperios, no es posible que el muchacho - que corresponde al locutor del enunciado- se identifique con el enunciador de los insultos, puesto que, al mismo tiempo le expresa su amor y, además, con la serenata pensaba halagar a la chica y granjearse su perdón; por lo tanto se trata de una situación absurda y el efecto cómico estriba en que en ese momento no hay rectificación alguna de los insultos que lanza el locutor. 
En un segundo momento entra el padre en escena y nos damos cuenta de que, efectivamente, el muchacho no estaba insultando a la chica sino que pretendía llamarla por su nombre y, de hecho, el padre así lo entiende, puesto que le hace la aclaración. La rectificación produce el segundo efecto cómico: su estado de ebriedad lo hizo confundir las palabras.

La situación graciosa consiste entonces en que, en este momento, el locutor se identifica con el enunciador de los insultos pero en la creencia de que no eran improperios los que profería, sino un simple llamado a la muchacha. Para el lector, el locutor también podría aparecer en un principio como identificado con el enunciador, y sus palabras (dado su estado de ebriedad), ser resultado del despecho. La rectificación del padre es lo que aclara la situación y lo que lleva a no identificar al locutor con el enunciador.

Veamos ahora el caso de la ironía. Como en el humor, el locutor de un enunciado irónico deja hablar, a través de su discurso, a un enunciador con el cual no se identifica. Se trata de una situación paradójica, puesto que a la vez que el locutor expresa directamente (y no por medio de un discurso referido) el punto de vista absurdo y, por lo tanto, asume la responsabilidad de este; el locutor lo presenta como el punto de vista de un enunciador con el que abiertamente no se identifica. Y para señalar que se distancia de ese enunciador, el locutor se vale de la evidencia situacional, de entonaciones particulares o de ciertas expresiones ya hechas, características del discurso irónico (;Qué bonito!).

La descripción de la conjunción pero - a la que este autor dedicó muchos análisis en el proceso de elaboración de la teoría de la argumentación en la lengua - también conlleva una interpretación polifónica ${ }^{7}$.

En un enunciado del tipo $X$ pero $Y$, el locutor presenta en el primer segmento un argumento $p$ a favor de una conclusión $r$, y en el segundo un argumento $q$ a favor de la conclusión inversa $(\text { no } r)^{8}$. Esta descripción general puede tener variantes, por ejemplo, cuando la expresión es cierto que o el adverbio ciertamente introducen el primer segmento.

Veamos un ejemplo: A le pregunta a B su opinión sobre la inmigración ilegal y $\mathrm{B}$ le responde:

Es cierto que (o ciertamente) la inmigración ilegal representa para muchos una oportunidad de salir de la pobreza, pero implica dejar sus países, abandonar a sus familias y contratar su fuerza de trabajo en condiciones casi siempre desventajosas.

$\mathrm{Al}$ emplear es cierto que (o el adverbio correspondiente), el locutor B atribuye a A una argumentación del tipo de: la inmigración ilegal es una oportunidad de salir de la pobreza, por consiguiente, vale la pena arriesgarse, argumentación que tal vez A no formuló explícitamente, pero que B le atribuye, y a la cual se opone mediante q: la inmigración ilegal implica dejar sus países..., por lo tanto, no vale la pena arriesgarse.

En el análisis de enunciados de este tipo Ducrot considera que aparecen en escena, por lo menos, cuatro enunciadores sucesivos: E1, E2, E3 y E4, a los que corresponden cuatro puntos de vista (pdv) diferentes:

- pdv1 según el cual la inmigración ilegal representa para muchos una oportunidad de salir de la pobreza $(p)$.

- pdv2 que da esa indicación como un argumento a favor de la conclusión $r$ : vale la pena arriesgarse.

7 (Cf. Ducrot 1984, pp. 229-30; Ducrot 2001 pp. 21-22). Cabe señalar que esta descripción, que para muchos analistas sigue siendo canónica, corresponde con una fase anterior de la teoría de la argumentación en la lengua, que en la actualidad ha evolucionado en la teoría de los bloques semánticos, desarrollada tanto por Oswald Ducrot como por Marion Carel.

8 Ducrot distingue los segmentos materiales que relaciona un conector (X Y) de las entidades semánticas $(p, q)$ que articula dicho conector. 
- pdv3 según el cual la inmigración ilegal implica dejar sus países, abandonar a sus familias y contratar su fuerza de trabajo en condiciones casi siempre desventajosas $(q)$.

- pdv4 que da la indicación anterior como un argumento a favor de la conclusión no $r$ : no vale la pena arriesgarse.

El locutor identifica a A con E1 y E2 y se identifica a sí mismo con E3 y E4. Ahora bien, poder especificar en el sentido del enunciado el origen de los puntos de vista, independientemente de los lazos que el locutor guarde con esos puntos de vista, implica, para Ducrot, mantener la noción de enunciador. En efecto, esta noción permite dar cuenta de situaciones en las que el sentido del enunciado identifica dos enunciadores con un mismo ser, pero atribuye al locutor actitudes diferentes en relación con cada enunciador, actitudes que, en un metadiscurso, equivaldrían a que el locutor afirmara: "estoy de acuerdo contigo en tanto que piensas esto, pero no en tanto que piensas aquello" (Ducrot, 2001, p. 21).

Tal es la situación en este ejemplo. Por el empleo de es cierto que (o de ciertamente), aun cuando el locutor reconoce que la inmigración ilegal representa una oportunidad de salir de la pobreza, no lo afirma por su propia cuenta (pdv1); y además rechaza que, aun cuando sea una oportunidad de salir de la pobreza, valga la pena correr el riesgo de inmigrar ilegalmente (pdv2). De ahí la necesidad de distinguir cuatro enunciadores, dos de los cuales no solo no se identifican con el locutor, sino que, además, este último mantiene lazos diferentes con cada uno.

En resumen, el locutor presenta, por una parte, una actitud de reconocimiento y, a la vez, de distancia en relación con el pdv1, y de rechazo en relación con el pdv2 y, por la otra, de adhesión con el pdv3 y el pdv4. Este ejemplo muestra una identidad de origen entre los enunciadores y los interlocutores (E1 y E2 se identifican con A y E3 y E4 con B).
Pero en este caso podría también considerarse que, en términos de B, A presenta $p$ como único argumento a favor de $r$. Por consiguiente es necesario introducir en el análisis del enunciado de B un punto de vista 5 adicional, según el cual la oportunidad de salir de la pobreza es no solo un argumento, sino también un argumento suficiente para concluir $r$. El origen de este nuevo punto de vista sigue siendo A, y la actitud del locutor en relación con el pdv5 es de rechazo: no basta con considerar que la inmigración ilegal sea para muchos la oportunidad (la única) de salir de la pobreza, para concluir que vale la pena arriesgarse. Por consiguiente, aun cuando se mantiene la identidad de origen (E1, E2 y E5 se identifican con A), el lazo del locutor en relación con los puntos de vista no es el mismo, puesto que aunque otorgue su acuerdo al punto de vista de E1, rechaza el pdv2 y el pdv5.

A manera de recapitulación, en lo que se refiere a la caracterización de los puntos de vista, Ducrot (2001, p. 39) considera dos situaciones. La primera cuando las palabras se presentan como habiendo sido efectivamente pronunciadas; en ese caso, hablaríamos de un discurso referido, ya sea literalmente o solo en la idea o la intención, y el origen de dicho discurso sería un locutor segundo (solamente un locutor puede presentarse como el origen de las palabras $)^{9}$, enmarcado en el habla del locutor principal.

Tal es el caso, por ejemplo, cuando en un diálogo uno de los participantes retoma lo que dijo su interlocutor (sin que se trate de una paráfrasis o de una repetición literal).

Así, si una mujer afirma, contestando a un marido que le reprochara haber hablado en exceso:

-¡Ah!, ¿soy indiscreta?:¡espera a que oigas a los demás, para ver si eso es cierto!

En este caso la mujer efectivamente produjo el enunciado en cuestión, y se identifica con la marca

9 Cuyas características, similitudes y diferencias con el locutor principal todavía están por determinarse. 
de la primera persona, pero no es la responsable de la aserción, ya que justamente refuta el calificativo, atribuyendo a su marido el considerarla indiscreta (aun cuando este último solo le haya reprochado una verbosidad excesiva que, en el razonamiento de la mujer, implica que él pensara que fue indiscreta).

Volviendo a la naturaleza de los puntos de vista, la segunda posibilidad es que se trate de palabras virtuales de un discurso que, de hecho, nadie pronunció, ni tal como se presenta ni de una otra forma cualquiera, y en ese caso el origen de esas palabras se atribuiría a los enunciadores.

En cuanto a la pertinencia teórica de las nociones de locutor y de enunciador, Ducrot considera que están ligadas a las dos funciones que desempeñan las palabras: por una parte, las palabras sirven para "constituir una representación lingüística de la realidad"10; dichas representaciones se relacionan con los enunciadores, los cuales "no hacen más que 'ver' las cosas, pero las ven a través de palabras". Por la otra, la función de las palabras también concierne la comunicación, es decir, la interacción discursiva, y esta segunda función es la que desempeña el locutor al asumir diversas posiciones en relación con los enunciadores y sus respectivas representaciones.

La concepción polifónica permite, pues, sacar a relucir como la descripción de un enunciado puede consistir en una especie de "puesta en escena" teatral, de diálogo o de polémica entre diversos protagonistas, uno de los cuales es el locutor.

\section{ScaPoLine: la teoría escandinava de la polifonía lingüística}

La teoría escandinava de la polifonía lingüística (ScaPoLine) se fijó el objetivo de suministrar una base lingüística que rigiera el estudio de la interpretación polifónica de los textos.
Basada en parte en la perspectiva de Ducrot ${ }^{11}$, la ScaPoLine reconoce dos niveles de análisis: el de la lengua y el del habla. A su vez distingue entre la frase (entidad semántica abstracta) y el enunciado (que corresponde con la realización concreta de una frase). La significación es el valor semántico que se atribuye a la frase y el sentido aquel atribuido al enunciado.

De acuerdo con esta teoría la polifonía forma parte del sentido del enunciado $y$, en el nivel de la lengua, la significación de la frase generalmente provee de instrucciones relativas a la polifonía observable en el nivel del sentido de los enunciados.

Una primera innovación de esta teoría es la noción de "pasaje polifónico" (Nølke, Fløttum y Norén, 2004, p. 25), que corresponde con una especie de "universo cerrado" en lo que concierne a las relaciones polifónicas. El pasaje polifónico es un puente que une los enunciados individuales al texto completo: un número $\mathrm{x}$ de enunciados conforman un pasaje polifónico $\mathrm{y}$, a su vez, un número $\mathrm{x}$ de pasajes polifónicos conforman un texto. Ahora bien, dada la dificultad que plantea para el análisis lingüístico delimitar las dimensiones de un enunciado y, además, debido al hecho de que, a menudo, dicho análisis incluso rebasa la frontera del enunciado, el pasaje polifónico permite soslayar ambos problemas, ya que se analizará siguiendo los mismos principios aplicables al enunciado.

La ScaPoLine distingue entre la "configuración polifónica", que remite al nivel del enunciado y que, por consiguiente, es un hecho observable, y la "estructura polifónica”, que corresponde con un hecho de la lengua.

La configuración polifónica está constituida por cuatro elementos: el "locutor en tanto que construc-

10 Para Ducrot (2001) es indispensable - dado que asume una posición estructuralista que cuestiona la posibilidad de describir la lengua por medio de entidades extralingüísticas — insistir en que las palabras "constituyen una representación de la realidad" y no que "expresen una representación supuestamente anterior y caracterizada como mental".

11 Para una revisión de los lineamientos teóricos de Oswald Ducrot, véase, por ejemplo, Les mots du discours, pp. 7-56. 
tor" (abreviado: LOC); los "puntos de vista" (abreviados: pdv); los "seres discursivos orígenes de los pdv" (abreviados: sd) y los "lazos enunciativos" (abreviados: lazos) que relacionan a los sd con los pdv.

Para la ScaPoLine (como para Ducrot), el locutor (LOC) es el responsable de la enunciación y juega dos papeles diferentes: el de construir los elementos que componen la configuración polifónica y el de presentar sus propios puntos de vista, haciendo hablar a un actor en su nombre.

Ahora bien, a diferencia de la teoría de la polifonía de Ducrot, la ScaPoLine desarrolla ampliamente la noción de punto de vista (Nølke, Fløttum y Norén, 2004, p. 31). Los pdv son entidades semánticas compuestas de un origen, un juicio y un contenido. Se formalizan de la siguiente manera:

$$
\text { [X] (JUZGA (p)) }
$$

En donde X simboliza el origen, JUZGA el juicio y $\mathrm{p}$ el contenido proposicional.

El origen de los pdv es una variable que, a nivel de la lengua, puede ir de la indeterminación total (por ejemplo en la negación, en donde muchas veces no es posible determinar el ser discursivo responsable del pdv positivo subyacente), pasando por diversos grados de determinación (cuando se emplean expresiones del tipo se dice que $x$, parece ser que $x$ ) hasta la completa determinación (como en el caso del discurso referido).

El juicio se expresa por medio de adverbios modales (tal vez, sin $d u d a$ ), de proposiciones parentéticas y, en última instancia, de la modalidad "es cierto que". Tanto el origen como el juicio de los pdv a menudo están sobreentendidos. La ScaPoLine considera la distinción juicio/contenido proposicional equivalente a la distinción modus/dictum, empleada tanto por los lingüistas como por los lógicos. Por otra parte, según su naturaleza, los pdv se subdividen en simples y complejos y, estos últimos, a su vez, en jerárquicos y relacionales.

Los pdv simples son independientes de los otros pdv que puede expresar el enunciado. Constan de un contenido semántico y de un juicio sobre dicho contenido; su origen está por determinarse y tienen la forma de una predicación (Juan estudia mucho).

Los pdv simples pueden tener un contenido semántico expuesto o presupuesto ${ }^{12}$. Ahora bien, todo enunciado contiene por lo menos un pdv simple cuyo contenido semántico es expuesto, es decir, explícito. Los enunciados también pueden vehicular puntos de vista que, en realidad, no juegan ningún papel en la configuración polifónica; tal es el caso, por ejemplo, de los pdv que expresan los presupuestos existenciales (en El amigo de Juan se presupone que existe un amigo de Juan o que Juan tiene un amigo).

Los pdv son simples presupuestos (por ejemplo los que contienen las subordinadas relativas y completivas o la significación de ciertos verbos como dejar de) que tienen la misma estructura que los pdv simples expuestos:

Mi hermano, a quien le gusta tocar el piano, llegará en unos instantes.

[X] (CIERTO (A mi hermano le gusta tocar el piano)).

Su única diferencia estriba entonces en su origen: el locutor del enunciado asume los pdv expuestos, mientras que la "opinión pública" se presenta como origen de los presupuestos.

12 Traduzco la distinción de Ducrot posé/présupposé como expuesto/ presupuesto. 
Los pdv complejos combinan pdv simples de diversas maneras. Como su nombre lo indica, los jerárquicos presentan una estructuración jerárquica: hacen recaer juicios exteriores sobre otros juicios. Tal es el caso de la negación: independientemente de cuál sea el contenido semántico del pdv1, el contenido semántico del pdv2 es que el pdv1 es injustificado, y por ello se refuta:

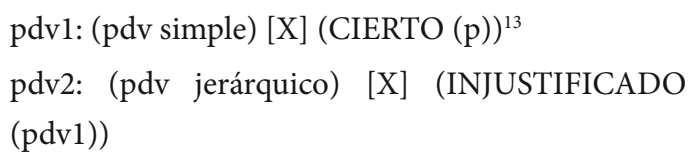

El discurso referido y los enunciados que comportan adverbios como tal vez también contienen pdv jerárquicos:

(Tal vez Juan ya llegó

pdv1: (pdv simple) [X] (CIERTO (Juan ya llegó))

pdv2: (pdv jerárquico) $[\mathrm{X}](\mathrm{TAL}$ VEZ (pdv1))

Como se puede apreciar en estas dos representaciones los pdv complejos, a diferencia de los pdv simples, no tienen la forma de una proposición que dé cuenta de un estado de cosas.

Por su parte, los pdv complejos relacionales precisamente relacionan entre sí los pdv simples o los complejos en el eje sintagmático. Un ejemplo lo ilustra el empleo de los conectores. En la estructura $p$ ya que q, el pdv complejo que expresa "ya que es $q$ es la causa de $p "$ (en otras palabras, esta expresión conjuntiva articula dos pdv de los cuales el segundo se presenta como origen del primero), y los términos p y $q$ corresponden con los dos puntos de vista simples: (pdv1) me caso y (pdv2) todo lo quieres saber.
Cabe señalar que, en este ejemplo particular, la relación que establece ya que concierne, no el pdv1, sino la enunciación del enunciado que lo contiene (lo que implica, desde luego, que el locutor del enunciado asuma y enuncie dicho pdv). En otras palabras, el ya que todo lo quieres saber justifica no el hecho de que me case, sino el de decírtelo, de avisarte sobre mi matrimonio (Ducrot, 1983).

Como dijimos anteriormente, tanto para Ducrot como para la ScaPoLine, el locutor tiene un status particular, dado que se trata de un ser discursivo que nunca entra en escena como origen de un pdv específico. Esta función está reservada a los enunciadores (en la posición ducroniana) y a los seres discursivos (para la ScaPoLine).

Así, para Ducrot, las actitudes del locutor en relación con los puntos de vista están mediatizadas por las actitudes que mantiene en relación con los enunciadores $^{14}$. A diferencia de la noción de enunciador, los seres discursivos (Nølke, Fløttum y Norén, 2004, p. 37) en la ScaPoLine se definen como imágenes de personas lingüísticas, es decir de seres del universo discursivo, representados por medio de sintagmas nominales, nombres propios, pronombres personales, dado que se trata de imágenes que construye el locutor, necesariamente subjetivas.

Entre los seres discursivos, LOC asigna a los protagonistas del acto de comunicación, es decir, a sí mismo y al alocutario (ALOC), dos imágenes distintas: el "locutor del enunciado" (lo), como origen de la enunciación, y el "locutor textual" (L), que posee todos los rasgos de una persona completa ${ }^{15}$. La mayoría de las veces lo no se representa explícita-

13 En donde «X» simboliza el origen, «CIERTO» el juicio y «p» el contenido proposicional.

14 Cf. supra donde expongo las razones que presenta Ducrot para mantener la noción de enunciador.

15 Esta distinción corresponde con la que propone Ducrot entre L: el locutor como tal, origen de la enunciación y $\lambda$ : el locutor como ser del mundo; cf. Ducrot 1984, pp. 200-1. 
mente (solo, por ejemplo, en el caso del yo, o de las marcas de la primera persona, de las proposiciones parentéticas de carácter metalingüístico o modal o en las expresiones performativas). Correlativamente distingue el alocutario del enunciado (ao) y el alocutario textual $(\mathrm{A})^{16}$.

En cuanto a las terceras personas corresponden naturalmente con los seres discursivos representados por los pronombres de la tercera persona, los nombres propios y los sintagmas nominales con referencia no genérica. En este caso la ScaPoLine introduce una subcategoría para distinguir los «terceros individuales» de los «terceros colectivos». Esta última categoría corresponde con la llamada opinión general, la cual, a su vez, consta de dos variantes: SEpolifónico ${ }^{17}$ y la LEY.

Es posible que la opinión general esté constituida por un colectivo en el que sus miembros sean individuos susceptibles de tomar la palabra y entonces se tratará de una categoría heterogénea, polifónica, en el interior de la cual pueden incluirse instancias de $\mathrm{L}$ o de A. Tal es el caso de expresiones como se dice que..., ustedes pretenden que..., aseguramos que...

Por otra parte, la forma impersonal también puede revestir un conjunto homogéneo de límites vagos que corresponde con la doxa, la ley, las ideas recibidas, las verdades eternas.

Estas dos categorías se diferencian entonces en que SE-polifónico es divisible en varias voces, mientras que la LEY, no.

En el caso de los contenidos presupuestos, por ejemplo, es posible que al no explicitarse el origen de un pdv, pueda atribuírsele a una categoría o a la otra, según sea la situación de enunciación o de in- terpretación. Así, en Pedro sabe que Juan vino, el pdv Juan vino podría correr por cuenta de la LEY o de un SE-polifónico restringido que podría comprender L, A o un tercero.

Por último, los "lazos enunciativos" también forman parte de la configuración polifónica que construye LOC. Esta categoría se subdivide en los "lazos de responsabilidad" y los "lazos de no responsabilidad". Su función es la de determinar la posición de los diversos sd (seres discursivos) en relación con todos los pdv (puntos de vista). Desde una perspectiva polifónica, los lazos de responsabilidad tienen una importancia capital, ya que su determinación forma parte del proceso de interpretación discursiva (Nølke, Fløttum y Norén, 2004, p. 44).

La ScaPoLine postula como principio general: "un sd es responsable de un pdv si, y solo si, este sd es el origen de dicho pdv". Así, por ejemplo, en la negación, la estructura polifónica misma (es decir, desde el nivel de la lengua) contiene instrucciones que indican que lo es el responsable del pdv2, pero no del pdv1:

\section{Juan no vino}

pdv1: [X] CIERTO (Juan vino)

pdv2: [lo] INJUSTIFICADO (pdv1)

En el proceso de interpretación, tanto de un enunciado como a nivel textual, es fundamental poder determinar el o los pdv de los que lo se responsabiliza. En segundo lugar será importante determinar los diversos lazos que lo establece con los otros pdv.

En lo que concierne a los lazos de no responsabilidad, es posible que la estructura polifónica dé instrucciones, sobre todo cuando se trata de los la-

16 Ejemplos en los que lo y ao aparecen explícitamente son: Claro que, pienso yo, no es posible aceptar semejante propuesta. Pero, como usted sabe, nunca hay que fiarse de nadie.

17 La ScaPoLine emplea en francés el término "On-polyphonique” para referirse a un tercero colectivo heterogéneo. Un posible equivalente en español del pronombre personal indefinido de la $3^{\mathrm{a}}$ persona del francés podría ser el pronombre reflexivo se. 
zos que conciernen a lo. Tal es el caso de los lazos de acuerdo, de desacuerdo, de refutación, neutros, etc., que pueden instaurarse cuando lo se declara no responsable de un pdv y lo cede a alguien más (por ejemplo en la estructura concesiva).

Es evidente que los conectores juegan un papel primordial en el establecimiento, tanto de los lazos de responsabilidad como de no responsabilidad. Volviendo al ejemplo Me caso, ya que todo lo quieres saber, de acuerdo con el análisis que propone Ducrot, el enunciado $Y$ ya que $X$ presenta en $\mathrm{X}$ un discurso $p$ que determina el discurso $q$, presentado en $\mathrm{Y}^{18}$. En otras palabras, el locutor de $\mathrm{X}$ está obligado a decir Y, y lo está debido a la información $p$ preexistente. Por consiguiente, lo se presenta como responsable de la enunciación del enunciado que contiene el pdv1 (Me caso), pero no del pdv2 (todo lo quieres saber), del cual lo solo se hace eco y cuyo responsable es el alocutario y más específicamente el alocutario textual (A). Por su parte, el origen del pdv relacional (“ $p$ es la causa de $q$ ”) sería SE-polifónico, en el que se incluye a $\mathrm{L}$.

Ahora bien, no solamente criterios de tipo semántico pragmático (como el análisis de los conectores) contribuyen a la clasificación de los lazos. También es posible recurrir a criterios de orden semántico lógico y, por ejemplo, referirnos a las expresiones que comentan el contenido proposicional a partir de las condiciones de verdad o de certeza (como la locución adverbial tal vez, me parece que o el adverbio ciertamente y la negación sintáctica). Es a partir del análisis de las expresiones que entran en estos criterios como la ScaPoLine propone que los lazos de no responsabilidad pueden considerarse refutativos (cuando se trata de la negación sintáctica) y no refutativos (cuando concierne el empleo de ex- presiones como tal vez, me parece que, ciertamente, etcétera).

Resumiendo, los indicadores de los lazos de responsabilidad y de no responsabilidad pueden clasificarse de la siguiente manera:

Lazos semántico pragmáticos de responsabilidad:

- Argumentativos: por consiguiente, por lo tanto (en la secuencia $X$ por consiguiente $Y$ el argumento $q$ que transmite $\mathrm{Y}$ se presenta como la consecuencia del argumento $p$ que transmite $\mathrm{X}$, consecuencia que se deduce de un razonamiento que parte de una lógica inferencial; lo es el responsable de $p$ y de $q$ y, a la vez, es el que razona) ${ }^{19}$.

Se trata de mi boda, por consiguiente yo decido a quien invito.

- Contraargumentativos: pero (lo es responsable solo del segmento que introduce pero).

Efectivamente, tu casa es bonita, pero no viviría en ella ${ }^{20}$.

- Reformulativos o reinterpretativos: en fin (en una estructura $p$ en fin $q$, el conector marca que lo es responsable de $q$, y también marca una relación de reformulación o de reinterpretación en relación con $p$ ).

Podemos ir al cine o a cenar; en fin, hacemos lo que tú quieras.

Lazos semántico pragmáticos de no responsabilidad

- Contraargumentativos: aunque (lo no es responsable del segmento que introduce la conjunción (i) o del que la precede (ii)).

18 Nuevamente aclaro que para Ducrot $X$ y $Y$ corresponden con los segmentos materiales que relaciona un conector, y $p$ y $q$ con las entidades semánticas que articula dicho conector.

19 Para una descripción más amplia $c f$. Nølke, Fløttum y Norén ibid., p. 89. Una descripción opuesta es la que presentan Ducrot y Carel en su semántica de los bloques argumentativos.

$20 \mathrm{Al}$ afirmar: Efectivamente, tu casa es bonita, lo reconoce, da su acuerdo, al pdv de A (el alocutario textual) pero no lo asume. 
(i) El análisis requiere de más argumentos, aunque acepto que es bueno.

(ii) El trabajo es ciertamente original, aunque tiene numerosas fallas ${ }^{21}$.

Lazos semántico lógicos de no responsabilidad

- Epistémicos: tal vez (lo no es responsable del pdv sobre el que recae la expresión tal vez, lo solo es responsable de la expresión misma, es decir, del comentario a propósito del pdv).

Tal vez hiciste solo el trabajo, pero no me parece bueno.

- Refutativos: no (la refutación muestra el carácter inadmisible del pdv sobrentendido).

No acepto tus excusas: son demasiado banales.

Un último lazo de carácter semántico que es necesario tomar en cuenta es el llamado lazo de representación, el cual corresponde con las comillas que marcan la no responsabilidad de lo de fragmentos o de enunciados completos.

Nølke, Fløttum y Norén llaman ampliada la versión de la ScaPoLine que propone un camino para ir del enunciado al texto en el análisis polifónico. La teoría parte de la estructura polifónica, es decir, de la frase (que corresponde con un hecho de lengua) para llegar, en una primera instancia, a la configuración polifónica, al nivel del enunciado (que viene a ser un hecho de habla). La configuración polifónica reviste un papel determinante, ya que sirve de puente para acceder al texto y desembocar en el análisis discursivo propiamente dicho. Por consiguiente, se trata de un análisis ascendente que tiene como propósito integrar los estudios lingüísticos a los discursivos.

Para lograr lo anterior, los autores proponen tres etapas (Nølke, Fløttum y Norén, 2004, p. 101):
1. Determinar la estructura $\mathrm{p}$.

2. Dar cuenta de las relaciones transfrásticas.

3. Relacionar los sd con una situación real (o ficticia).

Para determinar, en la primera etapa, la estructura polifónica es necesario determinar los pdv y proceder a establecer los lazos que los diversos sd mantienen con cada uno de ellos. Como vimos en su representación formal, cada pdv expresa su tipo o naturaleza (simple, relacional, jerárquica), el origen, el juicio y el contenido proposicional. Para determinar los diversos pdv, hay que tomar en cuenta marcas explícitas como adverbios, conectores, la negación sintáctica, las comillas, etcétera.

En la segunda etapa se lleva a cabo el paso al análisis textual. Para lograr este cambio de nivel, es necesario hacer uso del concepto de pasaje polifónico (pp) (cf. supra), el cual puede variar en extensión y comprender desde un enunciado simple o complejo hasta un conjunto limitado de enunciados. En esta etapa es necesario dar cuenta de los factores que conciernen la "coherencia textual polifónica": se reúnen los datos de la primera etapa con el fin de determinar la red de relaciones que se establecen entre los diversos sd y los pdv detectados en los enunciados que componen el pasaje polifónico. Los pdv que asume el locutor constituyen el cuerpo de dicha coherencia, pero la determinación de los lazos de no responsabilidad es igualmente indispensable para la interpretación textual (por ejemplo, para determinar cuándo los mismos sd se repiten).

La tercera etapa es la del análisis discursivo. En este estadio se procede a identificar los diversos sd para relacionarlos con seres reales o ficticios (en el caso de la obra literaria), con el fin de dar un sentido global al texto. En esta etapa se recurre al contexto en el sentido amplio del término y se incorporan al

21 Nuevamente, al afirmar en (i) acepto que es bueno y en (ii) el trabajo es ciertamente original, lo está simplemente otorgando su acuerdo al pdv de A. 
análisis características sobre el género, la temática y los personajes. Es igualmente en esta etapa cuando se determinan, a partir del conocimiento del contexto en el que el discurso se produce, las conclusiones ${ }^{22}$ hacia las que se orientan conectores como pero, incluso, etcétera.

No hay espacio aquí para poner en práctica esta propuesta de análisis tentativa que dejo para un trabajo posterior. Quisiera, sin embargo, concluir con una breve reflexión sobre un pasaje de Oscar Wilde:

Incluso los periódicos han degenerado. Ahora pueden ser absolutamente confiables. Uno lo siente conforme transita penosamente a través de sus columnas. Siempre acontece lo ilegible ${ }^{23}$.

La ScaPoLine formula, como hipótesis, el doble principio según el cual todo enunciado transmite, por lo menos, un pdv explícito del que lo es responsable. La anulación de este principio implica una situación particular como la que se encuentra en una lectura irónica (Nølke, Fløttum y Norén, 2004, p. 51).

Esta cita de Wilde es irónica. En efecto, una lectura irónica se da cuando existen incompatibilidades entre ciertos conocimientos, ideas o maneras de pensar comúnmente aceptados y la información que transmite un enunciado ${ }^{24}$. La entonación o el empleo de ciertas expresiones o de signos paralingüísticos también pueden dar cuenta de un sentido irónico.

En este caso, al afirmar que los periódicos han degenerado, uno esperaría (si se tratara de una afirmación no irónica) que la crítica fuera en el sentido de que no dicen la verdad, y de que en sus columnas siempre sucede "lo imposible". Como no es así, nos encontramos ante un discurso ostensiblemente irónico, en el que, a su vez, Wilde critica la pobreza y las deficiencias del uso del lenguaje en el medio periodístico.

Como vimos antes, de acuerdo con Ducrot (1984, p. 211), hablar de manera irónica equivale a considerar que el locutor presenta la enunciación como expresando la posición de un enunciador del que el locutor se distancia por considerar dicha posición absurda. Por consiguiente, a la ironía corresponde, en términos ducrotianos, un lazo de desacuerdo: lo declara inadmisible el pdv en cuestión pero, y esto es importante resaltarlo, esta actitud no corresponde con el objeto reconocido del habla. De igual forma, siguiendo la perspectiva de la ScaPoLine, la ironía es un caso de no responsabilidad que normalmente no deja huellas en la significación.

Buscando una interpretación de este pasaje y tratándose de una tentativa de análisis polifónico, mi interés es poder encontrar al o a los responsables de los puntos de vista que expresan. Ahora bien, para lograrlo la ScaPoLine considera que, en lo que concierne al análisis de textos auténticos (no de ejemplos construidos que sirven de ilustración) y particularmente de textos literarios, el procedimiento ascendente que parte del nivel lingüístico para desembocar en el literario se complica y es necesario llevar a cabo un constante ir y venir entre los diversos niveles de análisis.

Antes de proceder a la determinación de las estructuras polifónicas, hay que tomar en cuenta, pues, que no se trata, por ejemplo, de una entrevista hecha a Oscar Wilde, sino que es una cita proveniente de una de sus obras.

Las estructuras polifónicas de este pasaje podrían caracterizarse de la siguiente manera:

22 Dichas conclusiones conciernen a las descripciones que proponen Ducrot et al. (1980) de los conectores, en el marco de su teoría de la argumentación en la lengua.

23 La traducción es mía: "Newspapers, even, have degenerated. They may now be absolutely relied upon. One feels it as one wades through their columns. It is always the unreadable that occurs". Oscar Wilde 1969 [1889], p 971

24 No es mi intención ahondar aquí sobre una explicación que diera cuenta de la gestación de esta lectura irónica. Al respecto, la teoría de la relevancia de D. Sperber y D. Wilson (1995) propone considerar la ironía no como una antifrase (de acuerdo con la definición retórica tradicional), sino como un fenómeno de mención, haciendo referencia a la distinción clásica en lógica entre la mención de un término y su empleo.. 
(i)

pdv1 (pdv simple): [lo] (CIERTO (p1)), en donde p1 = 'los periódicos han degenerado'

pdv2 (pdv simple): [SE] (CIERTO (p2)), en donde p2 = 'otras cosas han degenerado'

pdv3 (pdv simple): [SE] (CIERTO (p3)), en donde p3 = 'la degeneración de los periódicos es más significativa que la degeneración de cualquier otra cosa'

pdv4 (pdv simple): [X] (CIERTO (p4)), en donde p4 = 'actualmente los periódicos pueden ser absolutamente confiables'

pdv5 (pdv simple): [SE] (CIERTO (p5)), en donde p5 = 'antes los periódicos eran confiables'

pdv6 (pdv jerárquico): [SE] (INJUSTIFICADO $(\operatorname{pdv} 5))$

(iii)

pdv7 (pdv simple): [lo] (CIERTO (p7)), en donde p7 = 'uno lo siente conforme transita penosamente a través de sus columnas'

pdv8 (pdv simple): [SE] (CIERTO (p8)), en donde p8 = 'a través de las columnas de los periódicos se transita penosamente'

pdv9 (pdv simple): [X] (CIERTO (p9)), en donde p9 $=$ 'siempre acontece lo legible'

pdv10 (pdv jerárquico): [lo] (INJUSTIFICADO (pdv9))

Los pdv 2 y 3 de (i) expresan los presupuestos que residen en la significación del adverbio incluso ${ }^{25}$. Por otra parte, los pdv 5 y 6 de (ii) corresponden con el sobreentendido que se infiere del adverbio ahora, sobreentendido que contiene dos pdv: la afirmación subyacente a la negación y la refutación de dicha afirmación. A su vez, el pdv 8 de (iii) expresa el presupuesto que reside en el sintagma verbal transitar penosamente. Por último, el pdv 9 expresa la afirmación subyacente al pdv 10, que expresa una refutación ${ }^{26}$.
En esta primera etapa del análisis, es posible considerar que el locutor lo es el responsable del pdv1 en (i), del pdv7 en (iii) y del pdv10 en (iiii).

De igual forma, el origen de los pdv 2 y 3 en (i), de 5 y 6 en (ii) y de 8 en (iii) es un SE-polifónico que podría, en algunos casos, incluir a L (el locutor textual). Por su parte, el origen del pdv 4 en (ii) y del pdv 9 en (iiii) es un tercero no identificado.

En cuanto a los lazos de no responsabilidad, en (ii) lo establece un lazo de no responsabilidad en relación con el pdv4 y en (iiii) lo constituye un lazo de refutación en relación con el pdv9.

En la segunda etapa y de acuerdo con una de las hipótesis que postula la ScaPoLine ${ }^{27}$, es posible concluir que hay identidad entre las tres imágenes de LOC: en (i), (ii), (iii) e (iiii).

Ahora bien, de hecho, en este pasaje la afirmación según la cual en la actualidad los periódicos pueden ser absolutamente confiables es susceptible de dos lecturas: una irónica, que ya mencionamos, y otra que asume abiertamente lo. En efecto, más adelante en ese pasaje, aclara que dicha confiabilidad radica en que en ellos siempre acontece lo ilegible.

Por consiguiente, el pdv4 en (ii) podría tener otra interpretación en la que lo aparecería como responsable:

(ii)

pdv4 (pdv simple): [lo] (CIERTO (p4)), en donde p4 = 'actualmente los periódicos pueden ser absolutamente confiables'. (Fin de cita extensa)

Pasando a la tercera etapa del análisis, cabe señalar que el pasaje polifónico estudiado forma parte de la obra La decadencia de la mentira, diálogo entre dos personajes: Cyril y Vivian. Este último escribe un artículo "The Decay of Lying: A Protest" que lee a su

26 Para un análisis de même (que posee el mismo valor argumentativo que incluso), cf. Anscombre, Ducrot 1983.

27 Si lo afirma que todo lo que acontece es ilegible es para oponerse, para refutar, a quien sostiene que los periódicos son legibles, que están bien escritos. 
amigo, en el que expone toda una teoría sobre el arte y concluye afirmando que el "mentir, el decir bellas cosas falsas, es el fin apropiado del arte" 28 . Su discurso es, pues, una apología de la mentira, en la que expresa una serie de paradojas que, como es clásico en Wilde, nos dejan pensando. Así, por ejemplo, critica al joven que empieza la vida con un don natural para la exageración pero que, sin darse cuenta, adopta hábitos de precisión o empieza a frecuentar la sociedad de los viejos y de los bien informados:

Ambas cosas son igualmente fatales para su imaginación, $[\ldots]$ y en poco tiempo desarrolla una mórbida y enfermiza aptitud para decir la verdad, empieza a verificar todas las aseveraciones hechas en su presencia, no titubea al contradecir a gente mucho más joven que él y, a menudo, termina escribiendo novelas que son tan parecidas a la vida que nadie puede creer en su verosimilitud ${ }^{29}$.

El locutor es, pues, Vivian, personaje no conformista que busca parodiar el discurso de la aristocracia victoriana.

Al respecto, Bajtín (1988, p. 253) propone una clasificación que sistematiza las diversas modalidades de discursos, atendiendo a su carácter univocal y bivocal. Los discursos bivocales son aquellos en los que es posible encontrar dos orientaciones de sentido, dos voces: una que se dirige hacia el objeto del discurso y otra hacia el discurso ajeno. El autor aprovecha la palabra ajena para sus propios fines, atribuye una nueva orientación semántica a una palabra que ya posee una y la conserva.

En esta segunda modalidad las dos voces no solo se encuentran distantes, aisladas sino que incluso se contraponen y entran en conflicto. En la parodia el autor cambia diametralmente la orientación del sentido de la palabra ajena. De manera ostensible y deliberada, esta última aparece con marcas, por su parte las intenciones del autor también se individualizan más claramente. Es posible parodiar un estilo, una manera de hablar, pensar o ver, y hacerlo tanto desde el punto de vista de una tipificación social como del carácter individual. La parodia puede aludir solamente a formas verbales superficiales o incursionar en profundidad en el habla ajena.

El fragmento anterior es, pues, un discurso bivocal que reproduce la palabra ajena con un cambio de acentuación. Como afirma Bajtín, en esta modalidad las dos voces se contraponen y entran en conflicto, de donde surge el sentido irónico.

En la Inglaterra de Wilde, se profesaba una gran adhesión e incluso veneración social y oficial por la verdad. Esto en parte, en gran parte, era artificial, una actitud cínica, hipócrita. Se mentía individual y colectivamente de muchas maneras, por ejemplo, la homosexualidad se practicaba de manera relativamente clandestina, aunque se toleraban prostíbulos de homosexuales que contaban entre su clientela a altos oficiales del ejército y a importantes miembros de la nobleza, el gobierno y el mundo cultural: Wilde era uno de ellos. Sin embargo la homosexualidad se consideraba oficialmente un delito y mucha gente, la gran mayoría, estaba de acuerdo en que así fuera. Esa era una forma social de mentir. Wilde no ocultaba ni disimulaba su preferencia: hacía ostentación de ella, desafiaba con ella las convenciones de su sociedad, incluso. Llevó ese desafío al extremo de ser condenado a la cárcel.

28 "El locutor en tanto constructor (LOC) de un enunciado aislado, situado en un texto monológico, con la imagen que construye de sí mismo en tanto que locutor del enunciado (lo), también es responsable de los enunciados que preceden y que siguen (salvo indicación explícita de lo contrario)” (Nølke, Fløttum y Norén, 2004, p.102)

29 Esta traducción y la siguiente nuevamente son mías. "[...] Lying, the telling of beautiful untrue things, is the proper aim of Art” (Wilde 1969 [1889], p. 992).

30 "Both things are equally fatal to his imagination, [...] and in a short time he develops a morbid and unhealthy faculty of truth-telling, begins to verify all statements made in his presence, has no hesitation in contradicting people who are much younger than himself, and often ends by writing novels which are so life-like that no one can possibly believe in their probability" (Wilde 1969 [1889], p. 973). 
En La decadencia de la mentira, el artificio de Wilde con respecto a la mentira, al parecer, consiste en elogiarla muy fundadamente y confundir en ese elogio, en un momento dado, el papel de la invención artística — que por necesidad, por definición, es ajeno a la verdad, sería una suerte de mentiracon los embustes en general. Parece buscar con eso desenmascarar la hipocresía de los que mienten ostentándose defensores o veneradores de la verdad, a cambio de la mentira honrada: aceptar, de entrada, que se miente sería una forma de ser veraz.

La ironía suele ser paradójica: para desnudarse de la hipocresía del mentiroso, ostentarse con la veracidad honrada del mentiroso (distanciándose pero, a la vez, asumiendo sus palabras). Y elogiar las virtudes de la nueva mentira, la del artista, porque, en el fondo, engaña menos que la supuesta verdad de los cínicos. No engaña: crea.

Los autores de la ScaPoLine afirman que, dado que el análisis polifónico que proponen parte del nivel lingüístico, es poco realista pretender llevar a cabo análisis similares de textos de grandes dimensiones. Aun cuando lo anterior es cierto, mi intención ha sido mostrar que, en realidad, no es posible obviar ninguno de los niveles de análisis aquí mencionados, ya que la polifonía va dejando huellas que hay que ir detectando y recopilando, desde el nivel de la lengua hasta el textual.

\section{Referencias}

Anscombre, J. (2009). La comédie de la polyphonie et ses personnages, Langue Française, 164, 11-31.

Anscombre, J, Ducrot, O. (1983). Largumentation dans la langue. Bruselas: Pierre Mardaga Editeur.

Bajtín, M. (1988). Problemas de la poética de Dostoievski, trad. de Tatiana Bubnova. México: Fondo de Cultura Económica. (Breviarios No. 417).

Bajtín, M. (1989). Teoría y estética de la novela. Trabajos de Investigación, trad. de Helena S. Kriúkova y Vicente Cazcarra. Madrid: Altea, Taurus, Alfaguara, S.A., (Serie Teoría y Crítica Literaria).
Carel, M., Ducrot O. (2009) Mise au point sur la polyphonie, Langue Française, 164, pp. 33-43.

Charuadeau, P. (1992). Grammaire du sens et de l'expression. París: Hachette.

Dessons, G. (2006). Émile Benveniste, l'invention du discours. París: Éditions IN PRESS.

Ducrot, O. (1983). Puisque: essai de description polyphonique, Analyses grammaticales du français. Etudes publiées à loccasion du 50 anniversaire de Carl Vikner. Etudes Romanes de l'Université de Copenhague. Revue Romane, número especial, 24, pp. 166-185.

Ducrot, O. (1984). Le dire et le dit. París: Minuit.

Ducrot, O. (1988). Polifonía y argumentación. Cali: Universidad del Valle.

Ducrot, O. (1996). Slovenian Lectures/Conférences Slovènes. Argumentative Semantics/Sémantique argumentative, I. Z. Zagar ed., Liubliana, Institutza Humanisticne Studije Ljubljana.

Ducrot, O. (2001). Quelques raisons de distinguer 'locuteurs' et 'énonciateurs', Les polyphonistes scandinaves/De skandinaviske polyfonister, No. 3, ed. M. Olsen, Roskilde trykkeri, pp. 19-41.

Ducrot, O., et al. (1980). Les mots du discours. París: Minuit.

Maingueneau, D. (2004). Pragmatique pour le discours littéraire. París: Nathan.

Nølke, H., Kjersti F. y Coco N. (2004). ScaPoLine. La théorie Scandinave de la polyphonie linguistique. París: Kimé.

Sperber, D. \& Deirdre W. (1995). Relevance: Communication and Cognition. Oxford: Blackwell.

Wilde, O. (1969). “The Decay of Lying” [1889] en Complete Works of Oscar Wilde, introd. Vyvyan Holland, (970-992). Londres y Glasgow.. 